\title{
FORMULASI TABLET SERBUK PISANG RAJA (Musa xparadisia AAB) SEBAGAI PENUTUP TUKAK LAMBUNG PADA TIKUS
}

\section{TABLET FORMULATION OF KING BANANA (Musa xparadisiaca $A A B$ ) AS GASTROPROTECTOR IN FEMALE WISTAR STRAIN RATS}

\author{
Iis Wahyuningsih \\ Fakultas Farmasi Universitas Ahmad Dahlan, Yogyakarta \\ avinagil@gmail.com
}

\begin{abstract}
Abstrak
Dari kajian empiris maupun beberapa penelitian terbukti pisang raja (Musa xparadisia $A A B)$ mempunyai potensi untuk dikembangkan menjadi sediaan gastroprotektor melalui mekanisme efek mukoadhesif. Sehingga diperlukan penelitian lanjutan untuk dibuat sediaan yang lebih praktis, stabil dan mempunyai dosis yang lebih seragam. Pada penelitian ini dipilih bentuk sediaan tablet yang mempunyai beberapa kelebihan seperti : praktis, aman dan relatif mudah pembagian dosisnya. Penelitian yang dilakukan meliputi : identifikasi buah pisang raja, pembuatan serbuk pisang raja, pembuatan tablet serbuk pisang raja, uji sifat fisik tablet serbuk pisang raja, uji mukoadhesif tablet serbuk pisang raja secara in vivo dengan menggunakan lambung tikus. Tablet serbuk pisang raja yang dihasilkan memenuhi kriteria tablet yang baik. Tablet serbuk pisang raja yang dihasilkan mempunyai kemampuan menutup tukak lambung tikus yang diinduksi dengan alkohol. Efektivitas efek mukoadhesif tablet serbuk pisang raja yang dihasilkan tidak berbeda bermakna dibandingkan dengan sukralfat $(p>0,05)$.
\end{abstract}

Kata kunci : pisang raja, mukoadhesif, tablet, tukak lambung 


\section{Abstract}

Mucoadhesive is a topic of current interest in the design of drug delivery system and treatment of peptic ulcers. This concept is based on the strength of adhesion of a protective material to the mucosa. King Banana (Musa x paradisiaca AAB) is often used in the treatment of abdominal pain. It has been suspected having muchoadhesive strength to cover peptic ulcer. The study was armed to formulate king banana tablet which has muchoadhesive ability to protect gastric mucosa become ulcer. The aim of peptic ulcer cover test was to see the ability of king banana tablet to covered ulcer at the groups test that received different treatment of the negative control group (solvent), the banana tablet suspension group, and sucralfate group. The ulcer severity was determined by scoring method. All experimental data were tested by SPSS analytical statistics. The result showed that king banana tablet has similar strength to peptic ulcer cover of sucralfat and not significantly different.

Key words : king banana tablet, peptic ulcers

\section{PENDAHULUAN}

Padatnya aktivitas dan tuntutan zaman yang serba modern memaksa masyarakat untuk bergaya hidup instan. Hal ini menjadi salah satu faktor masyarakat kurang menjaga kesehatan tubuhnya, mereka memenuhi kebutuhan untuk makan dengan makanan yang serba cepat dan mudah. Di sisi lain tuntutan gaya hidup dan ekonomi menyebabkan kemungkinan seseorang mengalami stress cukup tinggi. Hal tersebut dapat memicu timbulnya berbagai macam penyakit terutama yang berhubungan dengan saluran pencernaan salah satunya adalah tukak lambung/ maag/dispepsia (Dipiro dkk., 2005).

Berdasarkan penelitian di Amerika, kira-kira 500.000 orang tiap tahunnya menderita tukak lambung dan 70 persen di antaranya berusia 25-64 tahun. Sebanyak 48 persen penderita tukak lambung disebabkan karena infeksi $H$. pylori dan 24 persen karena penggunaan NSAID. Penggunaan alkohol juga dapat menyebabkan tukak lambung. Penggunaan alkohol secara terus menerus dapat mengikis dinding lambung dan merusak seluruh pertahanan lambung (Ramakrishnan dkk., 2007).

Beberapa obat yang lazim digunakan untuk tukak lambung adalah seperti analog prostaglandin, Pompa Proton Inhibitor, Antagonis Reseptor $\mathrm{H}_{2}$ serta sukralfat. Obat-obat bahan alam juga mulai dikembangkan, beberapa penelitian mengungkapkan ada beberapa tumbuhan alam yang dapat dijadikan sebagai obat tukak lambung atau gastroprotektif. Pisang Raja (Musa xparadisia $\mathrm{AAB}$ ) merupakan salah satu varietas tanaman pisang yang dilaporkan dapat menjadi alternatif dalam pengobatan salah satunya tukak lambung.

Ekstrak etanol dari buah pisang raja diilaporkan dapat meningkatkan 
akumulasi eiconosoids senyawa yang mirip prostaglandin PGE dan $\mathrm{PGI}_{2}$ serta leukotrien pada organ yang berbeda yang mengindikasikan dapat beraktivitas antitukak (Chattopadhayay dkk., 1987). Getah pisang raja juga terbukti dapat mempercepat penyembuhan luka insisi pada hewan coba mencit (Musmus culus) strain Balb/ c. Peneliti lain menyatakan mekanisme pengobatan tukak lambung pisang raja yaitu dengan cara memberi perlindungan pada mukosa lambung. Daging buah pisang raja mempunyai kemampuan merangsang pembentukan lendir dalam saluran pencernaan. Hasilnya, lapisan lendir di permukaan saluran pencernaan semakin tebal. Dengan begitu, permukaan saluran pencernaan akan terlindungi dari erosi asam lambung. Serbuk daging buah pisang raja juga memiliki kemampuan mempercepat penyembuhan tukak dengan cara mempengaruhi proses pembelahan selsel jaringan pada luka (Goel dkk., 2001).

Mukoadhesif adalah konsep yang dikembangkan para peneliti saat ini untuk mengatasi kerusakan dinding lambung yaitu dengan memberikan obat yang dapat menempel kuat pada dinding lambung. Dengan penempelan itu diharapkan sel-sel lambung tercegah dari iritasi lebih lanjut dan sel lambung dapat memperbaiki diri sendiri (Harding, 2006).

Saat ini bentuk sediaan yang dianggap mempunyai banyak kelebihan adalah sediaan tablet, karena dianggap lebih alami, tidak sulit, menyenangkan, stabilitasnya relatif tinggi, mudah dibawa dan aman dalam hal pemberian obat. Penelitian ini bertujuan memformulasi serbuk pisang raja menjadi tablet secara cetak langsung dan menguji efek penutup tukak lambung pada tikus menggunakan sukralfat sebagai pembanding.

\section{METODE PENELITIAN}

\section{Bahan}

Bahan yang digunakan adalah serbuk pisang raja, Aerosil, tablet sukralfat (Ulsidex ${ }^{\circledR}$ ), natrium $\mathrm{CMC}$, etanol absolut, eter, larutan formalin $0,5 \%$, larutan $\mathrm{NaCl}$ fisiologis, semua baku yang dipakai adalah pharmaceutical grade. Hewan coba menggunakan tikus putih betina galur Wistar (berat berkisar 150-200 g).

\begin{abstract}
Alat
Alat yang digunakan mencakup mesin cetak tablet (Manesty Machines LTD. Liverpool type B3B No. 8C 172), alat ukur kekerasan tablet (StokeMonsato), Roche Friabilator, Alat uji waktu hancur (Pharma Test-PTZ-E), alat uji mukoadhesif in-vitro, seperangkat alat bedah.
\end{abstract}

\section{Jalannya Penelitian}

a. Identifikasi buah pisang raja

Identifikasi tanaman dilakukan dengan melihat bagian buah secara mikroskopik. Identifikasi ini dilakukan dengan memotong buah pisang (Musa x paradisiaca $\mathrm{AAB}$ ) secara horizontal dan diamati di bawah mikroskop.

b. Pembuatan serbuk pisang raja

Pisang raja yang belum matang dan diperoleh di satu tempat diiris tipis-tipis dan diangin-anginkan. Bila sudah kering diblender dan diayak 
dengan ayakan 100 mesh agar diperoleh ukuran partikel yang seragam. Selanjutnya serbuk dikeringkan di oven selama satu jam agar didapat serbuk yang benar-benar kering.

\section{c. Pembuatan Tablet}

Formulasi tablet cetak langsung serbuk pisang raja tablet (502 $\mathrm{mg}$ ) yang dibuat mengandung: $\mathrm{R} /$ Serbuk pisang raja $500 \mathrm{mg}$ dan Aerosil ${ }^{\circledR} 2 \mathrm{mg}$

Semua bahan ditimbang sesuai formula untuk 100 tablet. Serbuk pisang raja dicampur dengan Aerosil ${ }^{\circledR}$ sampai homogen selama 10 menit kemudian langsung dicetak.

\section{d. Evaluasi Tablet}

Tablet serbuk pisang raja lalu dievaluasi, mencakup: keseragaman bobot, keseragaman ukuran dan kerapuhan.

e. Pembuatan suspensi tablet pisang raja

Dibuat larutan PVP 1\%, selanjutnya serbuk pisang dilarutkan ke dalam larutan PVP sampai terbentuk suspensi tablet pisang dengan konsentrasi $60 \%$ $\mathrm{b} / \mathrm{v}$.

\section{f. Uji penutup tukak lambung}

Sejumlah 40 ekor tikus putih betina (berat berkisar 150-200 g) yang telah diadaptasikan selama 7 hari dibagi secara acak ke dalam 4 kelompok :

Kelompok I : (kontrol), diberi larutan PVP $1 \%$.

Kelompok II : (etanol), diberi etanol absolute per-oral 1 $\mathrm{ml} / 200 \mathrm{~g}$ BB untuk menginduksi tukak lambung. Setelah 4 jam diberi larutan PVP 1\%.

Kelompok III : (etanol + sukralfat), diberi etanol absolute per-oral $1 \mathrm{~mL} / 200 \mathrm{~g}$ $\mathrm{BB}$, lalu setelah 4 jam diberi suspensi sukralfat dalam PVP $1 \%$ dengan dosis 18 $\mathrm{mg} / 200 \mathrm{~g} \mathrm{BB}$.

Kelompok IV : (etanol+ suspensi tablet pisang), diberi etanol absolute per-oral 1 $\mathrm{ml} / 200$ g BB, lalu setelah 4 jam diberi suspensi tablet pisang raja di dalam PVP $1 \%$ dengan dosis $18 \mathrm{mg} /$ $200 \mathrm{~g}$ BB.

Masing-masing kelompok dibagi menjadi 4 sub-kelompok secara acak untuk pengambilan data masing-masing pada waktu ke-2 dan ke-8 jam setelah pemberian obat atau larutan PVP $1 \%$. Untuk setiap waktu pengamatan, tikus dianestesi dengan eter lalu dikorbankan dengan cara dislokasi leher dan dibedah abdominalnya. Lambung dikeluarkan dan direndam di dalam $10 \mathrm{~mL}$ larutan formalin $0,5 \%$ selama 10 menit. Mukosa lambung dibuka dengan membedah lambung sepanjang kurvatora mayor, dicuci dengan $\mathrm{NaCl}$ fisiologis lalu diletakkan pada permukaan datar kemudian difoto dan diamati tukak lambung yang terjadi (Kaneko dkk, 1998).

Jumlah tukak yang terjadi dan besarnya diukur, keparahan tukak lambung melalui pemberian skor (Wattimena, 1982), seperti Tabel I. 
Tabel I. Skor keparahan tukak lambung

\begin{tabular}{|l|c|}
\hline \multicolumn{1}{|c|}{ Keadaan } & skor \\
\hline Normal & 1 \\
Kemerahan & 1,5 \\
Tukak berdiameter $0,5 \mathrm{~mm}$ & 2 \\
Tukak berdiameter $0,6-1,5 \mathrm{~mm}$ & 3 \\
Tukak berdiameter $1,6-4 \mathrm{~mm}$ & 4 \\
Tukak berdiameter $>4 \mathrm{~mm}$ & 5 \\
Perforasi & 6 \\
\hline
\end{tabular}

Persentase tukak dihitung dengan rumus

$$
\% H=\operatorname{Rn} / \operatorname{Ro} \times 100 \%
$$

$\% \mathrm{H}=$ Tingkat keparahan tukak lambung

$\mathrm{Rn}=$ Skor perlakuan

$\mathrm{R} 0=$ Skor kontrol

\section{Analisa Data}

Data hasil uji sifat fisik tablet dibandingkan dengan persyaratan tablet di Farmakope Indonesia IV. Data uji penutup tukak lambung dianalisis secara ANAVA

\section{HASIL DAN PEMBAHASAN}

\section{Identifikasi Buah Pisang}

Identifikasi tanaman dilakukan dengan melihat bagian buah secara mikroskopik. Identifikasi ini dilakukan dengan memotong buah pisang (Musa x paradisiaca AAB) secara horizontal. Pada identifikasi ditemukan ciri khas dari buah pisang yaitu adanya sel parenkim dan amilum. Seperti terlihat pada Gambar 1.

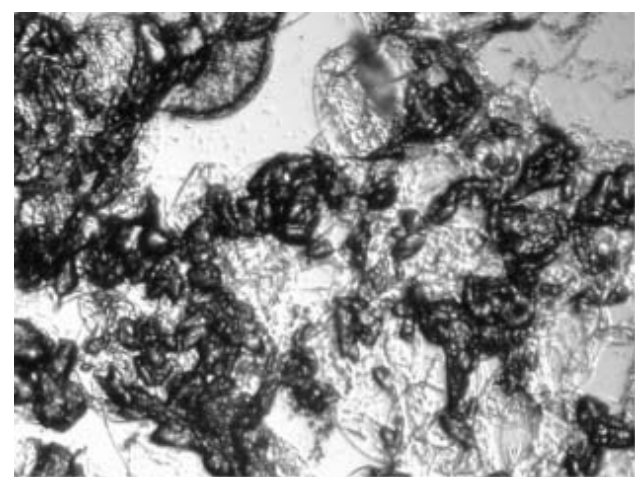

Gambar 1. Sel Parenkim dan Amilum buah pisang hasil identifikasi

Dalam identifikasi ini hanya dilakukan sebatas ciri khas buah pisang saja, karena jenis pisang raja merupakan merupakan persilangan antara "Musa" dan "Paradisiaca" menjadi bentuk varietas baru dengan penamaan Musax paradisiaca AAB (Valmayor dkk, 2000).

\section{Uji Fisik Tablet Pisang}

Hasil evaluasi tablet yang dihasilkan tersaji pada Tabel II.

Tabel II. Hasil uji fisik tablet serbuk pisang raja

\begin{tabular}{|c|l|c|}
\hline No & Parameter Uji & $\begin{array}{c}\text { Pengamatan } \\
\text { ( } \pm \text { SD) }\end{array}$ \\
\hline 1 & $\begin{array}{l}\text { Keseragaman } \\
\text { bobot }(\mathrm{mg})\end{array}$ & $506,64 \pm 0,58$ \\
2 & Ketebalan (mm) & $3,04 \pm 0,58$ \\
3 & Kerapuhan $(\%)$ & $0,89 \pm 1,23$ \\
\hline
\end{tabular}


Dari pemeriksaan keseragaman bobot tablet serbuk pisang yang diuji ternyata memenuhi persyaratan keseragaman sediaan pada Farmakope Indonesia edisi IV (Anonim, 1995) karena $\mathrm{CV}$-nya $=5 \%$. Kerapuhan merupakan parameter yang menggambarkan sifat ketahanan fisik tablet dalam melawan tekanan mekanik dan getaran serta menunjukkan kekuatan ikatan partikel-partikel pada bagian tepi

\section{Uji penutup tukak lambung}

Uji penutup tukak lambung bertujuan melihat daya penutupan tablet serbuk pisang yang dibuat suspensi dalam melindungi lambung dari tukak. pengamatan dilakukan dengan skoring ke- parahan tukak, kemudian data hasil pengamatan dianalisis. Hasil tersebut tersaji dalam Tabel III.

Tabel III. Hasil pengamatan tukak lambung

\begin{tabular}{|lcc|cc|}
\hline \multirow{2}{*}{ Perlakuan } & \multicolumn{2}{c|}{ Rata-rata skor $( \pm$ SD) } & \multicolumn{2}{c|}{$\begin{array}{c}\text { Tingkat Keparahan Tukak } \\
\text { (\%) }\end{array}$} \\
\cline { 2 - 5 } & $\mathbf{2 ~ ( j a m )}$ & $\mathbf{8}(\mathbf{j a m})$ & $\mathbf{2 ~ ( j a m )}$ & $\mathbf{8}$ (jam) \\
\hline Kontrol & $1 \pm 0,00$ & $1 \pm 0,00$ & 100 & 100 \\
Etanol & $2,67 \pm 0,52$ & $3,33 \pm 0,47$ & 267 & 333 \\
Etanol+ sukralfat & $1,14 \pm 0,44$ & $1,16 \pm 0,40$ & 114 & 116 \\
$\begin{array}{l}\text { Etanol + suspensi } \\
\text { serbuk pisang }\end{array}$ & $1,17 \pm 0,28 * \#^{\wedge}$ & $1,33 \pm 0,61 * \#$ & 117 & 133 \\
\hline
\end{tabular}

* Berbeda bermakna terhadap perlakuan etanol saja pada $\mathrm{p}<0,05$ diuji dengan Anava

\# Berbeda tidak bermakna terhadap perlakuan etanol + sukralfat pada $p>0,05$ diuji dengan Anava

$\wedge$ Berbeda tidak bermakna terhadap perlakuan 8 jam pada $p>0,05$ diuji dengan Anava

permukaan tablet yang ditandai sebagai massa partikel yang berjatuhan atau terlepas dari tablet melalui beban pengujian mekanik (Ansel, 1985). Tablet yang baik mempunyai susut bobot tablet setelah uji kerapuhan tidak lebih kecil dari $1 \%$ dari bobot mula-mula (Parrott, 1971). Tablet pisang yang dihasilkan memenuhi kriteria kerapuhan yang dipersyaratkan.
Induksi tukak dalam penelitian ini menggunakan etanol 96\%. Etanol merupakan penginduksi tukak lambung yang cepat dibanding penginduksi lain seperti asam salisilat karena etanol dapat mengerosi mukosa lambung sehingga cepat menyebabkan tukak lambung seperti pada penelitian yang dilakukan oleh Ben, dkk (2008).

Pada penelitian ini menggunakan sukralfat sebagai pembanding yang merupakan polimer bioadhesif yang mempercepat penutupan luka pada tukak 
lambung dan tukak duodenum melalui pembentukan kompleks dengan eksudat proteinaceus yang menempel pada tukak. Kompleks ini menutupi tukak dan melindungi dari serangan asam, pepsin dan garam empedu lebih lanjut (Li dkk, 1993).

Pada kelompok kontrol terlihat lambung dalam keadaan normal. Keadaan lambung kelompok yang diberi etanol saja ditemukan tukak terutama di bagian korpus lambung. Kelompok yang diberi sukralfat setelah diinduksi etanol dapat menghambat keparahan tukak hingga $35 \%$, sedangkan suspensi tablet pisang dapat menghambat keparahan tukak hingga 33\%.

Pada penelitian ini pengamatan tukak lambung dilakukan pada 2 dan 8 jam, setelah dilakukan uji Anava, ternyata tidak ada perbedaan yang signifikan antara skor tukak lambung pada pengamatan 2 dengan 8 jam.

Secara keseluruhan terlihat tablet buah pisang dapat menekan terbentuknya tukak. Mekanisme penutup tukak dari tablet buah pisang dapat disebabkan beberapa kemungkinan diantaranya karena terjadi ikatan antara buah pisang dengan asam sialat pada mukus. Mekanisme lain yang dapat terjadi adalah terbentuknya ikatan hidrogen antara pisang dengan komponen lain dari mucin. Disamping itu adanya asam lambung menyebabkan tablet serbuk pisang mengembang dan membentuk gel yang menempel pada mukus sehingga dapat melindungi mukus dari kerusakan lebih lanjut.

\section{KESIMPULAN}

1. Tablet serbuk pisang raja yang dihasilkan memenuhi kriteria tablet yang baik.

2. Tablet serbuk pisang raja yang dihasilkan mempunyai kemampuan menutup tukak lambung tikus yang diinduksi dengan alkohol hingga $33 \%$. Efektivitas efek penutup tukak lambung tablet serbuk pisang raja yang dihasilkan tidak berbeda bermakna dibandingkan dengan sukralfat $(p>0,05)$.

\section{DAFTAR PUSTAKA}

Anonim, 1995. Farmakope Indonesia. Edisi IV. 696-697. Departemen Kesehatan Republik Indonesia. Jakarta.

Ansel H.C.. 1985. Pengantar Bentuk Sediaan Farmas. Edisi IV. 251-258. Universitas Indonesia. Jakarta.

Ben, E.S., Lucida, H., Syafitriana, P.. 2008. Formulasi Tablet Kitosan dan Uji Daya Mukoadhesifnya Sebagai Penutup Luka pada Tukak Lambung Tikus, Prosiding Ikatan Sarjana Farmasi Indonesia ke II, Yogyakarta.

Chattopadhayay, S., Chaudhuri, S., Ghosal, S..1987. Activation of peritonial macrophages by Sitoindosides IV, an antiulcerogenic acylsteryl glycoside from Musa paradisiaca, Indiana Journal of Pharmacy; $53: 16$. 
Dipiro, T.J., Talbert, R.L., Yee,G.C., Matzke, G.R., Wells, B. G., Pasey, L. M.. 2005. Pharmacotherapy:A Pathofisiologic Approach, Edisi VI, 630-634, The MacGraw Hill Companies, Inc.

Goel, R.K., Shairan, K., Rao, ChN, Raman, A.. 2001. Role of gastric antioxidant and anti-Helicobacter pylori activities in the antiulcerogenic activity of plantain banana (Musa sapientum var paradisiana), Indian $J$ Expl Biol , 39 : 7 19-22.

Harding, S.E.. 2006. Trends in mucoadhesive analysis, $\mathrm{NCMH}$ Laboratory University Of Nottingham, Sutton Bonington, UK. Trends in food and science technology No.17 (255-262).

Kaneko, K., T. Mitsuma, H. Nagai, K. Kusugami, T. Iyo \& S. Mori. 1998. Central Action of Adrenomedullin to Prevent Ethanol-Induced Gastric Injury Through Vagal Pathway in Rats. Am. J. Physiol Regulatory Int. Comp. Physiol. 274: 1783-1788.

Li SP, CM Pendhakar, GN Mehta, MG Karth dan KM Feld. 1993. Sucralfat as bioadhesive gastric intestinal retention system ;
Primary Evaluation, Drug Dev. Ind. Pharm, 19(19), 2519-2537.

Parrott, E. L.. 1971. Pharmaceutical Technology Fundamental Pharmaceutics, 73-86, 158-169, Burgess Publishing Company, Minnepolis, Minnesota.

Ramakrishnan, Kalyanakrishnan, dan Salinas, R.. 2007. Peptic Ulcer Disease,//http:www.pubmed.gov, diakses tanggal 9 Maret 2010.

Valmayor. R.V., Jamaluddin, S.H., Silayol, B., Kusumo, S., Danh, L.D., Pascua, O.C., Espino, R.R.C.. 2000. Banana Cultivar Names and Synonyms In South Eat Asia. International Network for the Improvement of Banana and Plantain Asia and The Pacific Office, Los Banos, Laguna, Philippines. INIBAB ISBN 97191751-2-5.

Wattimena, $\quad$ J.R. 1982. L-Hypoprotenemie

Experimentale Chez Le Rat, Explotation Pharmacocinetique Du Modele. These Doct'eur D'Etat Es Sciences Pharmacetiques. Faculte De Pharmacie, Universite Monpellier. hal : 17-23. 